\title{
Development of Warning System for Preventing Collision Accident on Construction Site
}

\author{
Soungho Chae \\ Kajima Technical Research Institute, Tobitakyuu2-19-1, Chohushi, Tokyo, Japan, chae@kajima.com
}

\begin{abstract}
This paper describes the development of a personal warning system for preventing construction site accidents involving workers and heavy equipment. The required functions were established on the basis of a past accidents model. The system was designed to send a warning via wireless from a server computer to a worker and relevant parties according to estimation of distance between worker and equipment. RFID technology was used to estimate the distance. A warning message was defined as a means of sending information about danger to the worker and relevant parties. Parties receiving a warning were set up for each case, and the contents of the warning message were prepared accordingly. An experimental prototype device for sending a message from a server computer to a smart-phone was made under a wireless local area network, and it was clarified that to accept a warning message and to send a response.
\end{abstract}

Keywords: Safety management, Collision accident, Warning, RFID, Wireless device

\section{Introduction}

Several types of vehicles and heavy equipment, such as cranes and excavators, are used on construction sites to increase labour efficiency. This kind of equipment plays a crucial role in planning the work processes of building structures. The construction manager is required to plan vehicle zones and safety facilities. However, the number of accidents in which workers are struck by heavy equipment caused by negligence is increasing. In 2007, in the Japanese construction industry, more than 3,800 persons (about 19\% of the total) suffered injuries due to collisions with vehicles or heavy equipment that required 4 days or more for recovery [1].

Construction managers recognize the need to address this problem through a comprehensive approach to accident prevention. A method is necessary to complement accident prevention techniques such as Toolbox Safety Talk and Hazard Identification, which are conventionally performed to assist in avoiding accidents. The author has designed a Collision Accident Prevention System (CAPS) that uses an RFID device based on accident issues [2].

The objective of this study was to develop a warning system as a part of the CAPS. Past collision accidents were analyzed to clarify causative factors. The basic function of the warning system was thus designed on the assumption that data on the location of heavy equipment and workers is available. Finally, a concept of a warning device was proposed with a user interface and communication protocol. Function of Waring system

Basic Concept

CAPS supports accident prevention involving vehicles, heavy equipment and workers using working area data of each object. The working area is the space bounded by the reach of heavy equipment. An RFID (Radio Frequency Identification) device and a data communication system are used to estimate the size of the working area. The CAPS monitors the working area of all objects on the site and calculates the positional relation of heavy equipment and workers. When it is determined that a worker is in the restricted area of heavy equipment, a message warning of the danger of a collision is sent to the worker and concerned parties.

Analysis of Past Accidents

Past accidents involving heavy equipment are analysed to model error occurrences that could not be prevented by common warning tools using, e.g., light or sound. The error model is made for hydraulic excavators, lifts, truck cranes, tower cranes, etc. The items of the model are as follows.

1) Contact part of equipment 
2) Accident location

3) Task of worker

4) Error of worker, concerned parties, or manager causing accident

For example, the model of accidents involving hydraulic excavators shows the bucket as the most common contact part and the body as the second. Accident location was below or at ground level, where excavator usage is assumed, and the worker's task was work control, ground arrangement, excavation assistance, etc. Workers' errors included entering within the operating range of the machine, assuming a forced work posture, and wearing insufficient safety gear. Errors of concerned parities, i.e., excavator operators in this model, were lack of awareness of a worker's presence before starting to operate the machine. Managers' errors included defective safety plans, lack of a spotter, and ignoring of safety training. The modelling result clarified the factors affecting collision accidents.

\section{Setup of System Functions}

The author set up the following five functions for a warning system on the basis of the past accidents model.

1) Send worker a warning

This function reduces instances of workers ignoring warnings, which is likely to occur in conditions of continuous unrelated warning beeps. To enable him to recognize a danger, a warning is sent to a worker who could potentially access a heavy equipment working area. A direct warning message to a worker is expected to raise his awareness of a potential collision.

2) Send concerned parties information

This function enhances collision avoidance behaviour of a worker who received a warning. Concerned parties become aware of the collision potential and direct the worker to a safe area. Concerned parties include operators, spotters and signal men.

3) Ensure time for awareness

This function provides sufficient time for a worker who has received a warning to avoid a dangerous situation. A prompt warning enables the worker to escape from danger without panic or hesitation and the operator to check the movement range of his machine.

4) Set warning contents according to task

This function prevents workers from adopting a blaze attitude due to warning habituation. A worker who receives the same warning for all situations could try to avert the danger without confirming the true situation. The worker is required to confirm the dangerous situation according to the particular item of equipment and situation based on the warning information.

5) Require worker to respond

This function supports the judgment of whether a manager should directly warn a worker who is in a dangerous area. A reply is required of a worker who has received a warning as the result of recognition and avoidance of danger. At the same time, a list of workers who disregard the warning is sent to the concerned parties and the safety of worker is verified by the concerned parties.

\section{Warning System Design}

Area Definition for W arning

The author defined the working area of heavy equipment as a danger zone, and set up the area surrounding the danger zone as a confluence zone and safety zone [Figure-1]. The size of danger zone is determined by maximum range of equipment's movement. The confluence zone is designed according to the migration speed of equipment, the shape of site and the process of project. A worker who is in the confluence zone is at risk of becoming in a dangerous situation. CAPS was designed to send a warning to a worker who is monitored to be in a confluence zone or a danger zone.

\section{System Flow}

CAPS sends a warning by wireless from the administrative server to a worker and to relevant parties according to the estimation of distance between workers and equipment [Figure-2]. If a worker is in the confluence zone, his information is collected from a database and necessary cautions are sent to him and to relevant persons such as operators and spotters. 
A reply to a warning is required in order to verify reception and execution. If there is no reply within a specified time from a worker who is in the confluence zone, the relevant persons are required to confirm the situation and to ensure the worker's safety.

If a worker is in the danger zone, although emergency stop and alarm activation are necessary, this system is aimed at the sent warning which is estimated from the monitoring results.

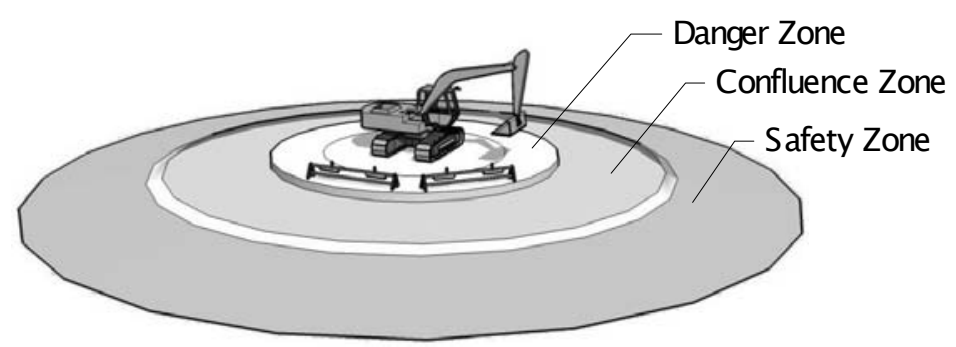

Figure-1. Defined area image for warning

Data Input

On construction sites, workers of different affiliations work at their individual tasks. Thus, to enable individual workers to recognize the danger to their particular situation, it is necessary to optimize the warning contents for each worker. This system defines persons, heavy equipment, and administration as three categories that receive a warning [Figure-3]. Persons are divided into two, relevant and nearby, and spotters and signalmen were also added.

Individual information about participants is inputted to the warning system in order to select a suitable warning for the worker judged to be in danger. The individual information is classified into general and concerned. The general information specifies the individual who receives a warning, and the concerned information is limited to participants who supervise individuals in danger.

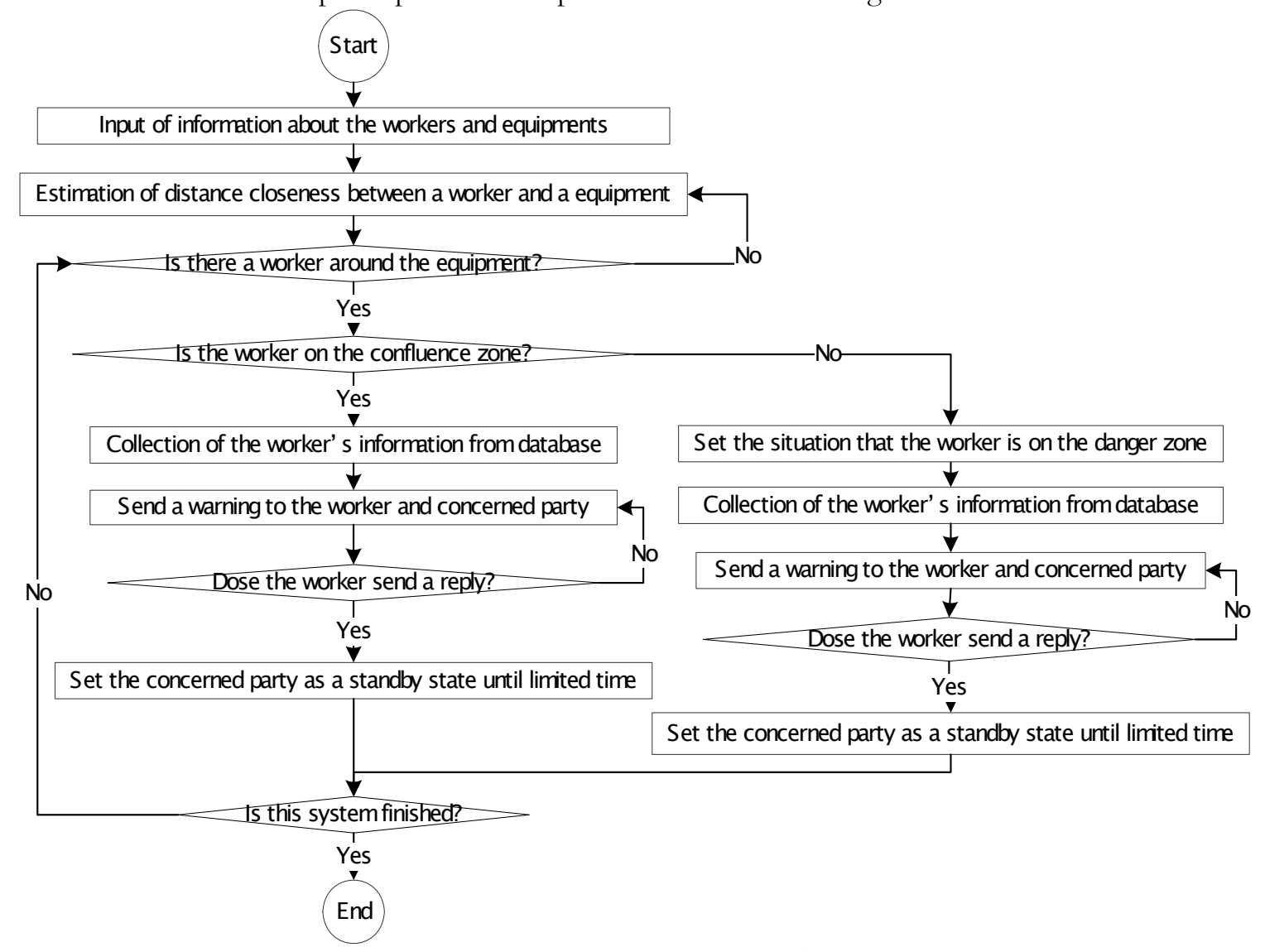

Figure-2. System flow to send warning 


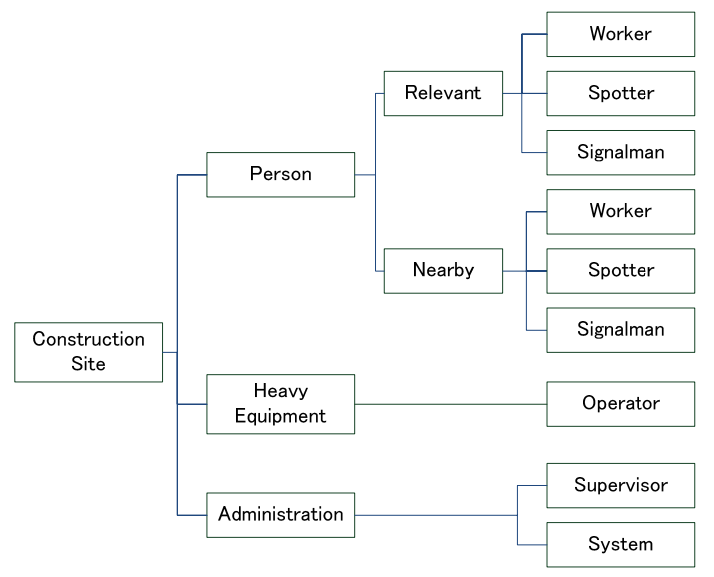

Figure-3. Classification of system participant

Table-1, Participants and input data

\begin{tabular}{c|c|c}
\hline Participant & \multicolumn{2}{|c}{ Input data } \\
\hline \hline \multirow{2}{*}{ Person } & General & $\begin{array}{c}\text { Name, Tag ID, Device address, } \\
\text { Affiliation, }\end{array}$ \\
\cline { 2 - 3 } Heavy \\
Equipment & Concern & Equipment model number \\
\cline { 2 - 3 } & General & Model number, Tag ID \\
\hline Administration & Concern & $\begin{array}{c}\text { Operator's name } \\
\text { Spotter' name } \\
\text { Signalman's name }\end{array}$ \\
\cline { 2 - 3 } & General & Device address \\
\hline
\end{tabular}

\section{Estimation of Distance from Equipment}

The distance from the worker to the heavy equipment, which is used to judge the collision potential, is estimated from the working area information. The active type RFID was selected as the method of working area collection.

An RFID device consists of readers and tags. It periodically emits an identification number using a battery, so the object to which the tag is attached becomes identifiable. The tag is given to the worker and to the heavy equipment that needs working area information. The electric wave of a tag may be reflected and absorbed by the body of the equipment depending on the frequency band. In order to reduce the number of warning malfunctions, it is also necessary to install two or more tags.

The RFID reader receives the ID number from an RFID tag that exists within the range of the recognition area. The size of the recognition area varies according to the radio signal strength. The existence area of the object that has the received ID number is determined from the installation position of the RFID reader. The installation positions are determined according to the plane of the actual site. If the number of installation readers is large, it is assumed that the estimation accuracy is improved, but this would involve an increase in cost and in volume of data to be processed.

The working area of workers and equipment is estimated to exist in the vicinity of the reader's position using the ID data collected from each RFID reader. However, the estimation result has noise due to the electric wave characteristics. The author proposed a noise reduction method using RSSI (Radio Signal Strength Indication) [3][4].

The distance from equipment to a worker is estimated from the working area data. When the estimation result indicates that the worker is in the same working area as the equipment, the worker is treated as being in a danger area. When the estimation result indicates that the worker is in an area adjoining the equipment working area, the worker is treated as being in the confluence zone. It is necessary to set the boundary of the adjoining working area according to the moving speed of the heavy equipment. 


\section{Definition of Warning Message}

The role of a warning is to greatly decrease the possibility of accident to a worker and related parities. Generally, warning lights and beeping sounds are used on construction sites. A worker who perceives a warning light or beeping sound is implicitly forced to get away from the danger, but there is insufficient information about what is going on around him. It is possible to reduce a worker's inadvertent error when trying to avoid the danger by providing him with information about the situation. In this system, a warning message is defined as a means for sending information about danger to a worker and related parties. The warning message is sent from an administration server when a worker enters a confluence zone.

The warning message to the worker was set up for four cases.

Case-1). A worker who is related directly to the heavy equipment work is in the confluence zone.

Case-2). A worker who is not related to the heavy equipment work is in the confluence zone.

Case-3). A response to a warning is sent.

Case-4). A response to a warning is not sent.

Participants who receive a warning are set up for each case, and the contents of the warning message are prepared accordingly. It is then checked whether the participants need to send a response when they receive a warning message.

Figure- 4 and Figure- 5 show examples of warning messages concerned with hydraulic excavation for case- 1 and case- 2 .

The relevant worker, operator, and system are set up as the participants in Figure-4. The warning message of ["(worker's name), you are near the (equipment' name). Be careful to avoid being struck."] was prepared for the relevant worker. The worker's name and the equipment's name in the message are extracted from the database that inputted the individual information. The worker called by name can improve his consciousness of warning and confirm the situation from the equipment' name. The relevant worker who received the warning message needs to reply to the system administrator.

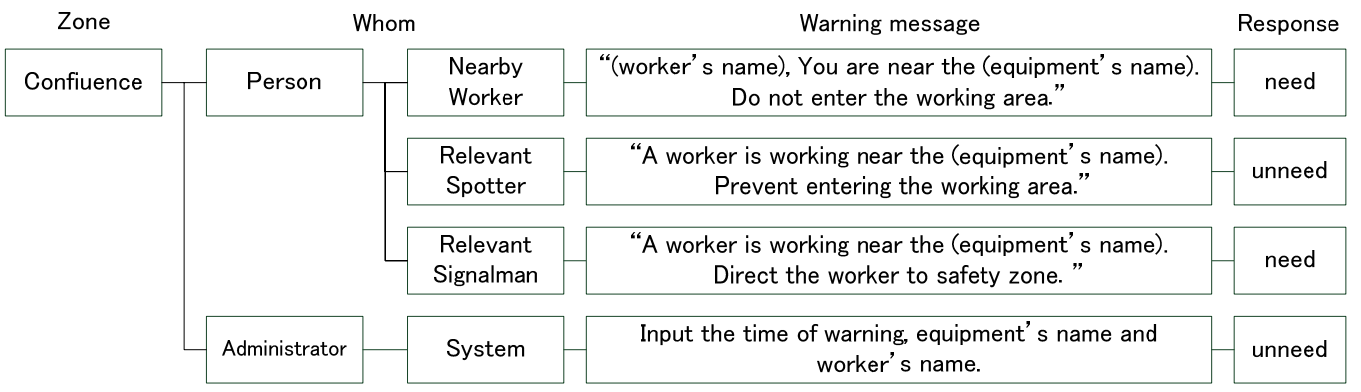

Figure-4. Example of warning message on the case-1)

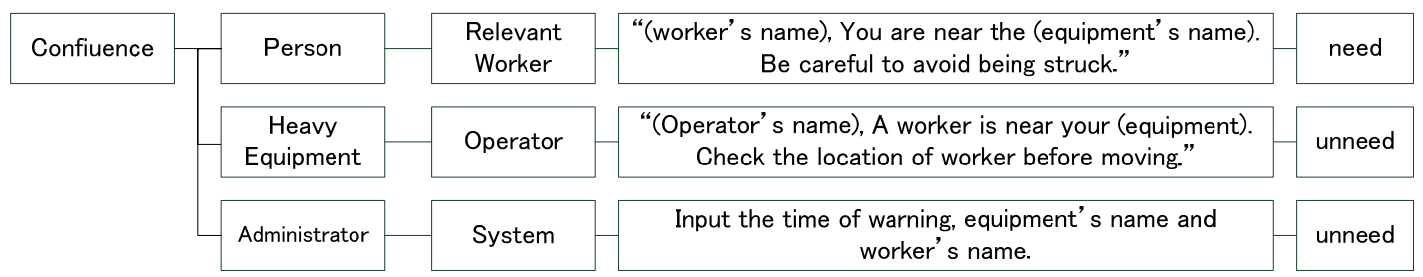

Figure-5. Example of warning message on the case-2)

\section{Development of Warning Device}

\section{Basic Concept}

The warning system that sends the message is composed of four parts: an active type RFID reader, a worker, a piece of heavy equipment, and an administrator server [Figure-6]. Since the worker and equipment are moving on the site, each part transmits and receives data through a wireless network. A smart-phone was selected as a personal device for receiving the warning message from the administrator server, and for 
sending the response. A smart-phone is a device for handling several media formats such as voice and text via the telecommunications network.

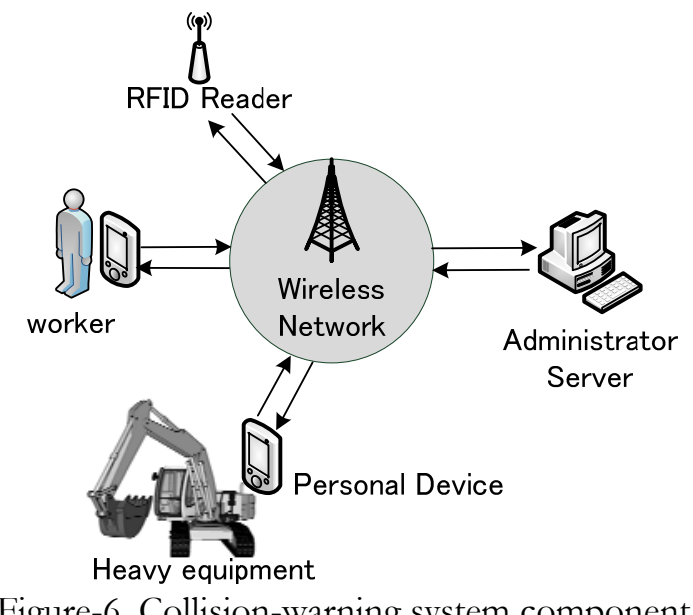

Prototype

An experimental prototype for sending a message from the server computer to the smart-phone was made under the wireless local area network. The operating system of the smart-phone was Window Mobile 6 Professional, and Microsoft Visual Studio 2005 was used as a software development environment.

The administrator server detects the worker who is in a dangerous situation second by second, and sends a signal that includes a command to play the warning message. Usually, voice and letter are used as the information media, but this system adopted voice media so that the gaze duration for confirming the message is less than that of the letter media. The network load is reduced by preliminarily downloading the audio files of warning message and sending only the IDs of file to each device.

A wireless headset for hearing a message and replying to it is used by Bluetooth network. There is a possibility that manual operation of the device could create an accident situation. Therefore, it is not to stop working hands necessary for operation. The voice-recognition function that is fitted into a smart-phone helps device operation such as incoming signals and calling from spoken worlds.

\section{Conclusion}

The basic concept and functions of a warning system for preventing collision accidents was proposed. The results show that the warning system optimized for individual people is efficient in reducing a worker's inadvertent error, recognizing warning information sharing by concerned parities, and confirming avoidance. A smart-phone was selected as a communication device for receiving messages and responding to them. Acceptance of a voice message and responding via a wireless network was verified by a prototype.

\section{Acknowledgement}

This work has been supported by a Grant-in-Aid for Scientific Research on Priority Areas (B) No.20360282 of the Japan Society for the Promotion of Science (JSPS).

\section{References}

[1] Japan Advanced Information Center of Safety and Health , (Webpage 2008.10.23) http://www.jaish.gr.jp/information/sokuhou.html

[2] Soungho CHAE \& Tomohiro YOSHIDA (2008), A study of safety management using working area information on construction site, $25^{\text {th }}$ ISARC, 292-299.

[3] Soungho CHAE \& Naruo KANO (2005) A location system with RFID technology in building construction site, 22 $2^{\text {nd }}$ ISARC, 43(1)-(6).

[4] Soungho CHAE \& Naruo KANO (2007), An estimation method of working area with RFID technology, $5^{\text {th }}$ ICCPM $/ 2^{\text {nd }}$ ICCEM, 47(1)-(8). 